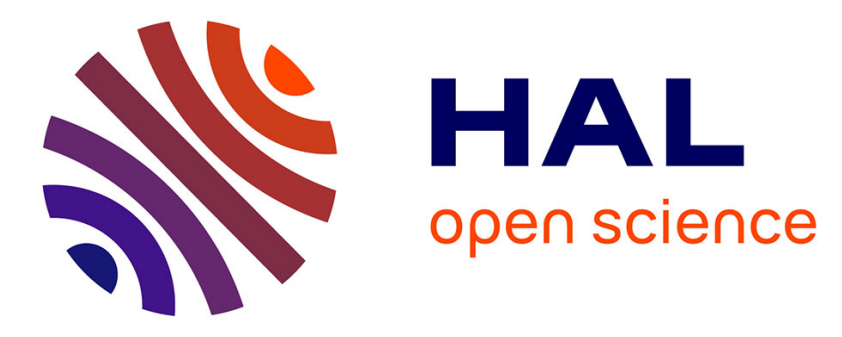

\title{
Merging gradient-based methods to improve benchtop NMR spectroscopy: A new tool for flow reaction optimization
}

Shrikant Kunjir, Mireia Rodriguez-Zubiri, Vincent Coeffard, François-Xavier Felpin, Patrick Giraudeau, Jonathan Farjon

\section{To cite this version:}

Shrikant Kunjir, Mireia Rodriguez-Zubiri, Vincent Coeffard, François-Xavier Felpin, Patrick Giraudeau, et al.. Merging gradient-based methods to improve benchtop NMR spectroscopy: A new tool for flow reaction optimization. ChemPhysChem, 2020, 21 (20), pp.2311-2319. 10.1002/cphc.202000573 . hal-02999906

\section{HAL Id: hal-02999906 https://hal.science/hal-02999906}

Submitted on 20 Nov 2020

HAL is a multi-disciplinary open access archive for the deposit and dissemination of scientific research documents, whether they are published or not. The documents may come from teaching and research institutions in France or abroad, or from public or private research centers.
L'archive ouverte pluridisciplinaire $\mathbf{H A L}$, est destinée au dépôt et à la diffusion de documents scientifiques de niveau recherche, publiés ou non, émanant des établissements d'enseignement et de recherche français ou étrangers, des laboratoires publics ou privés. 


\title{
Merging gradient-based methods to improve benchtop NMR spectroscopy: A new tool for flow reaction optimization
}

\author{
Shrikant Kunjir, Mireia Rodriguez-Zubiri, Vincent Coeffard, François-Xavier Felpin, Patrick Giraudeau, \\ and Jonathan Farjon*
}

Abstract:

Emerging low cost, compact NMR spectrometers that can be connected in-line to a flow reactor are suited to study reaction mixtures. The main limitation of such spectrometers arises from their lower magnetic field inducing a reduced sensitivity and a weaker spectral resolution. For enhancing the spectral resolution, the merging of Pure-Shift methods recognized for line narrowing with solvent elimination schemes was implemented in the context of mixtures containing protonated solvents. One more step was achieved to further enhance the resolution power on compact systems, thanks to multiple elimination schemes prior to Pure-Shift pulse sequence elements. For the first time, we were able to remove up to 6 protonated solvent signals simultaneously by dividing their intensity by 500 to 1700 with a concomitant spectral resolution enhancement for signals of interest from 9 to 12 as compared to the standard $1 \mathrm{D}^{1} \mathrm{H}$. Then, the potential of this new approach was shown on the flow synthesis of a complex benzoxanthenone structure.

\section{Introduction}

Better understanding chemical reactions is a long standing goal of synthetic chemists. Detecting and monitoring the molecular changes in a complex reaction mixture allows optimizing the reaction conditions for better conversions and selectivities. NMR is undoubtedly one of the most versatile techniques to identify and quantify components of reacting mixtures in real time.

High-field NMR is able to monitor real time reactions in a flow setting [1], but it is relatively difficult to implement due to the bulky environment and operating costs of high-field spectrometers.

Dr. S. Kunjir, Dr. M. Rodriguez-Zubiri, Dr. V. Coeffard, Prof. F.-X. Felpin, Prof. P. Giraudeau, Dr. J. Farjon. Université de Nantes, CNRS, CEISAM, UMR 6230, 44000 Nantes, France

*E-mail: jonathan.farjon@univ-nantes.fr

Supporting information for this article gathers $1 \mathrm{D}^{1} \mathrm{H}, 2$ WET180NOE and $\mathrm{m}$ W5 1D spectra, as well as detailed SNRs for multiple solvent suppression schemes alone and merged with TSE PSYCHE for indole derivative and solvent (DMF/EA) signals as compared to ${ }^{1} \mathrm{H}$. In the field of the flow synthesis, 2D TOCSY maps, as well as an assigment table, $1 \mathrm{D}^{1} \mathrm{H}$ in comparison to $1 \mathrm{~W} 5 \mathrm{TSE}$ PSYCHE spectra for sake of resolution, measured SNRs as well as linewidth at $5 \%$ height as compared to ${ }^{1} \mathrm{H}$ are showed for products $\mathbf{1}$ and 5 .
Fortunately, a new generation of benchtop NMR spectrometers has emerged, which are compact [2], cryogen free, low cost, and can be easily coupled to a reactor. However, the online monitoring of chemical reactions remains difficult due to the inherent limitations of low field NMR: a low sensitivity and a weak spectral resolution.

The performance of benchtop NMR spectrometers has been significantly improved by including gradient coils, making it possible to implement high-resolution pulse sequences of the kind typically used at high field to study complex reacting mixtures. Thus, 2D ultrafast methods were applied to reaction monitoring and authentication [3]. DOSY experiments were also reported and applied to the demixing of drugs formulations [4]. More recently, Pure-Shift (PS) methods [5] were implemented for the first time on a benchtop spectrometer, allowing significant line-narrowing in complex mixtures of small- to medium-sized molecules [6].

In addition to these advanced pulse-sequence developments, the study of reaction mixtures with possibly various mixed protonated solvents make it crucial to selectively suppress multiple and intense undesired peaks from solvents or other compounds in order to detect the smallest ones coming from analytes of interest. Towards this aim, gradient-based solvent elimination schemes have been compared on a benchtop spectrometer [7] and applied to reaction monitoring $[8,9]$. These developments have shown that benchtop NMR could be made more efficient by capitalizing on methodological developments made at high field. But while such proof-of-concept studies have shown the potential of gradient-based pulse sequences to improve the performance of benchtop spectroscopy, such potential could be pushed even further by combining tailored pulse sequence blocks to optimize the detection of signals of interest in a complex mixture. In this paper, we describe and evaluate the combination of several of the above-mentioned approaches for multiplying the resolutive power of compact instruments to better detect analyte ${ }^{1} \mathrm{H}$ signals in mixtures of protonated solvents.

First, we assess the efficiency of merging several solventsuppression blocks like multiple WET180 [10] either in a successive or interleaved fashion (see Figure 1). WET180 will be combined to NOESY 1D [11] able to remove the faraway contribution for making n WET180NOE (see Figure 1). Moreover, multiple WATERGATE W5: m W5 [12] (see Figure 1) is also evaluated and these two multi-suppression families are compared in terms of signal resolution and sensitivity. Such multi-elimination schemes have never been implemented on a benchtop NMR instrument in the context of reaction mixtures, and can help 
removing numerous unwanted intense protonated signals like for those from solvents.

Then, in order to further improve the resolution of relevant analyte signals, a novel approach is implemented, based on the combination of multiple solvent eliminations with PS techniques (Figure 1). Among ${ }^{1} \mathrm{H}$ homodecoupling sequences of interest, we chose to investigate the potential of TSE PSYCHE (Triple Spin Echo Pure Shift Yielded by Chirp Excitation) [13] recognized as the best compromise between sensitivity losses and resolution gain for small sized molecules [6]. Merging TSE PSYCHE with multi-elimination sequences forms a novel approach to push further the capabilities of each block taken individually.

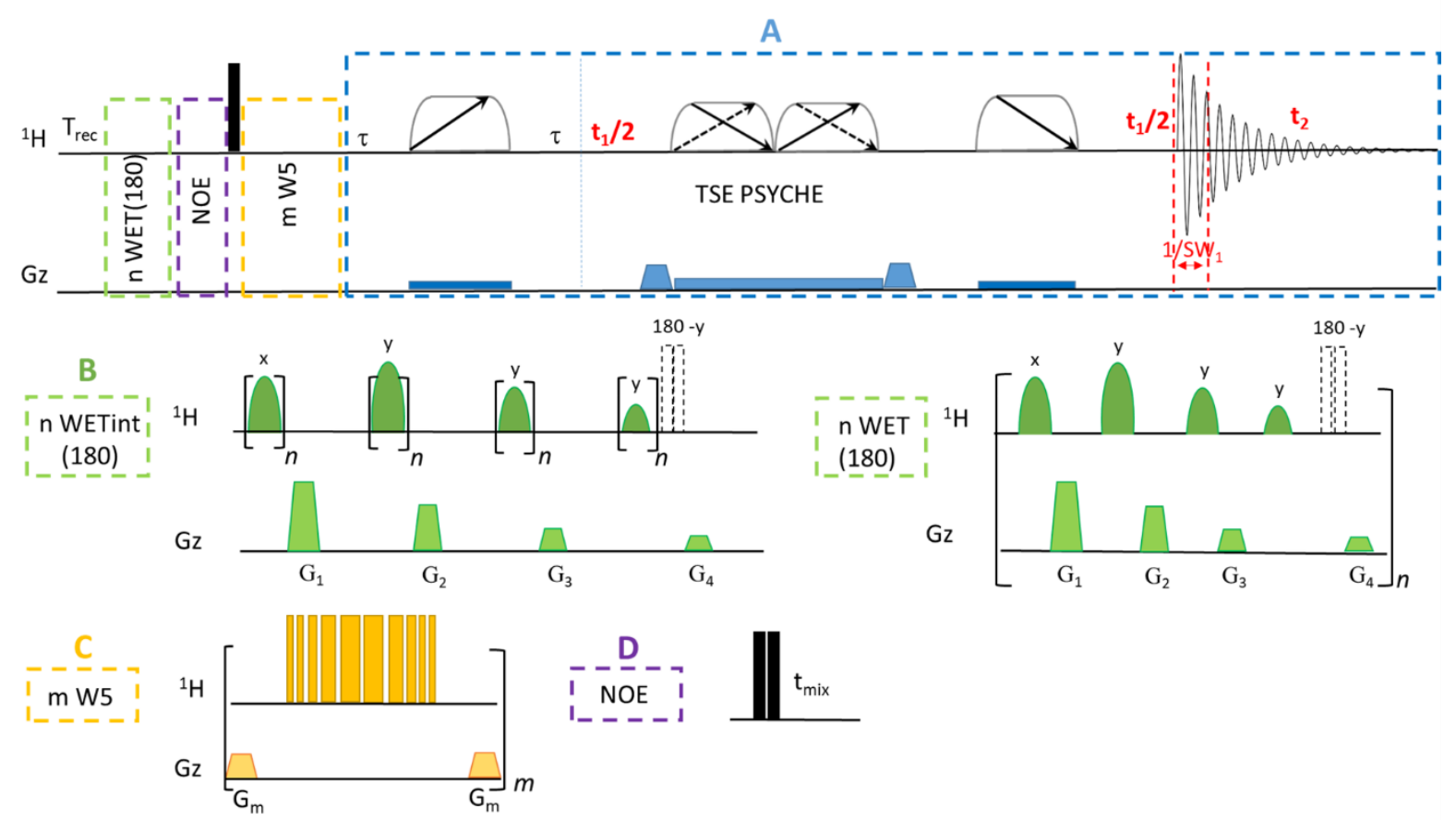

Figure 1. Pulse sequences for solvent eliminated Pure-Shift ${ }^{1} \mathrm{H}$ experiments used in this work are composed on different blocks. A Triple echo based method (TSE PSYCHE) with $\mathrm{G}_{1}: \mathrm{G}_{2}: \mathrm{G}_{3}: \mathrm{G}_{4}: \mathrm{G}_{5}: \mathrm{G}_{6}=57: 10: 21: 5: 33: 10, \phi_{1}: \mathrm{x},-\mathrm{x}, \mathrm{x},-\mathrm{x}, \mathrm{x},-\mathrm{x}, \mathrm{x},-\mathrm{x} ; \phi_{2}: \mathrm{x}, \mathrm{x}, \mathrm{x}, \mathrm{x}, \mathrm{x}, \mathrm{y}, \mathrm{y}, \mathrm{y}, \mathrm{y}, \mathrm{y} ; \phi_{3}: \mathrm{x}, \mathrm{x}, \mathrm{y}, \mathrm{y}, \mathrm{x}, \mathrm{x}, \mathrm{y}, \mathrm{y} ; \phi_{4}: \mathrm{x}, \mathrm{x}, \mathrm{x}, \mathrm{x}, \mathrm{x}, \mathrm{x}, \mathrm{x}, \mathrm{x} ; \phi_{\mathrm{acq}}: \mathrm{x},-\mathrm{x},-\mathrm{x}, \mathrm{x},-$ $\mathrm{x}, \mathrm{x}, \mathrm{x},-\mathrm{x}$; The gradients $\mathrm{G}_{\mathrm{i}}$ have a trapezoidal shape and are expressed in $\%$ of the maximum gradient coil amplitude $\left(16 \mathrm{G}^{-\mathrm{cm}^{-1}}\right)$. Each non-encoding gradient depicted by a Gaussian shape has a $1 \mathrm{~ms}$ duration is followed by a $500 \mu$ s stabilization delay. An additional gradient pulse (75\%) was used during the recycling time to get rid of unwanted coherences. B A double WET180 scheme with $n=2$ either in interleaved ( 2 WET180int) or successive (2 WET180) manner is using four Gaussian pulses having $81.4^{\circ}, 101.4^{\circ}, 69.3^{\circ}$ and $19^{\circ}$ angles prior to the excitation $[7] \mathrm{G}_{1}: \mathrm{G}_{2}: \mathrm{G}_{3}: \mathrm{G}_{4}=90: 45: 22.5: 11.25$, to remove solvent signals. $\mathbf{C}$ A multiple W5 scheme (m W5) [12] directly after the excitation can be used as an excitation sculpted way to remove 1 or 2 signal(s) with one W5 block. Successive W5 have been used and phase of the first half of each W5: $\mathrm{x}, \mathrm{x},-\mathrm{x},-\mathrm{x}, \mathrm{x}, \mathrm{X},-\mathrm{x},-\mathrm{x}$ and $-\mathrm{x},-\mathrm{x}, \mathrm{x}, \mathrm{x},-\mathrm{x},-\mathrm{x}, \mathrm{x}, \mathrm{x}$ for the second half of W5. In this work $\mathrm{G}_{\mathrm{m}}=1$ to 4 have been used. For $4 \mathrm{~W} 5, \mathrm{G}_{1}: \mathrm{G}_{2}: \mathrm{G}_{3}: \mathrm{G}_{4}=42: 33: 22: 45$. For $3 \mathrm{~W} 5, \mathrm{G}_{1}: \mathrm{G}_{2}: \mathrm{G}_{3}=42: 33: 22$. For $2 \mathrm{~W} 5, \mathrm{G}_{1}: \mathrm{G}_{2}=42: 33$. For $1 \mathrm{~W} 5, \mathrm{G}_{1}=42$. D An additional NOESY $1 \mathrm{D}$ block tunable with the mixing time $\mathrm{t}_{\text {mix }}$ can be used to remove the fareway solvent signal in exchange with the one in the sensitive volume [11]. Single and double black rectangle are depicting $90^{\circ}$ and $180^{\circ}$ pulses respectively.

With this aim, two criteria were chosen to evaluate the performance of these multi-pulse sequences. Sensitivity is evaluated through Signal-to-Noise ratios (SNR), and resolution is evaluated by the linewidth at $5 \%$ height, which is more adapted to multiplets than at $50 \%$ height. An initial assessment of these methods is described on a model mixture with two protonated solvents. Then, the best ultra-resolved strategy is applied to the optimization of the flow synthesis of a benzoxanthenone, an analogue of natural product carpanone, as a case study.

\section{Results and discussion}

\subsection{Evaluating multiple suppression techniques}

In order to assess the different techniques for removing the different solvent signals, an indole derivative was used as a model and dissolved in dimethylformamide (DMF) and ethyl acetate, (EA) (see Experimental Part) usually used in synthetic chemistry and have different ${ }^{1} \mathrm{H}$ signals. Huge signals coming from DMF close to $2.90,3.00$ and $8.00 \mathrm{ppm}$ as well as EA are easily detectable: a quadruplet at $4.12 \mathrm{ppm}$, a singlet at $2.02 \mathrm{ppm}$ and a triplet at $1.26 \mathrm{ppm}$. With intense DMF signals, baseline distorsions modulate the phase of other surounding smallest signals that are also partially overlapped (Figure S1). In this context, different solvent suppressing techniques were evaluated, first alone then followed by a TSE PSYCHE scheme to further enhance the spectral resolution (see Figure 1). 
The following strategies were evaluated to remove the six signals coming from the protonated solvents: WATERGATE W5 was implemented with either 2, 3 or 4 blocks, [12] as well as two different 2 WET180NOE methods (Figure 1). For 2 WET180NOE schemes, two selective bands were considered: one for the $\mathrm{H}^{\mathrm{N}}$ of DMF and a second larger one for methyl groups of DMF and EA (see Experimental part).

We first optimized the 2 W5 pulse sequence (Figure 1), with one block focusing on DMF signals and the other one on EA signals. This scheme was not found optimal for removing the six protonated signals as expected (Figure S2). Then, 3 W5 was implemented by dedicating one W5 block for the two signals of DMF, the second for the singlet $\left(\mathrm{CH}_{3} \mathrm{CO}\right)$ and the quadruplet $\left(\mathrm{CH}_{2}\right)$ of $\mathrm{EA}$, and the third one was dedicated to the triplet $\left(\mathrm{CH}_{3}\right)$ of EA. Under these conditions, the six signals were efficiently reduced at $1-2 \%$ of their average SNR as compared to $1 \mathrm{D}^{1} \mathrm{H}$ (see Figure 3.A and S3.B for details). Moreover, SNRs for the indole derivative remained almost unaffected with $98 \%$ of the 1D averaged SNR. The 4 W5 version with an additional W5 block for DMF - 2 W5 blocks are used for removing it - gave close results as compared to $3 \mathrm{~W} 5$ in terms of solvent elimination performances despite smaller averaged SNR (see Figure 3.A and S3.A), certainly due to the longer elimination scheme during which T2 relaxation induces signal losses. In comparison, the 2 WET180NOE pulse sequence induced a much larger loss in sensitivity (80-85\%) with slightly better SNRs for the shorter interleaved version which is less affected by $\mathrm{T} 2$ related sensitivity losses (see Figure 1 and Figure 2). Even if WET-based methods are expected to be more selective for solvent elimination due to their more tunable Gaussian pulses (see Experimental Section), the $\mathrm{m}$ W5 technique shows some sensitivity losses -from 2 to $19 \%$ - presumably due to T2 relaxation effects but also to the $m$ W5 nulling area impacting nearby indole signals. Thus, a careful optimization of $\mathrm{m}$ W5 nulling delays is essential to prevent any signals of interest to be reduced or removed. The nulling width is dictated by inter pulse delays. For example for 2 W5 (see Fig. S2), the methyl ${ }^{1} \mathrm{H}$ signal of indole has $92 \%$ of the ${ }^{1} \mathrm{H}$ SNR (see Fig. S3.A). It is slightly impacted by the 2 W 5 centered on the methyl signals of DMF. The difference in chemical shift between DMF and indole methyls is close to $0.7 \mathrm{ppm}$. Thus, an estimated nulling width of $\pm 0.7 \mathrm{ppm}-60 \mathrm{~Hz}$ at $43 \mathrm{MHz}$ - is a realistic value for inter pulse delays in the range of $4 \mathrm{~ms}$ (see table 2).

In terms of resolution, $\mathrm{m}$ W5 techniques efficiently reduce the linewidth at $5 \%$ height by an average factor from 4 to 5 compared to 1D without solvent suppression (see blue arrows in Figure S2 and 4). These narrowing effects are due to the important reduction of DMF and EA signals whose tails were strongly overlapped with those of the indole derivative signals on the ${ }^{1} \mathrm{H}$ spectrum (see blue arrows in Figure S1). Moreover, 4 W5 provides cleaner in-phase lineshapes than 2 and 3 W5 (see Figure S2), probably due to the compensation of J-modulation effects over several W5 blocks. Overall, $\mathrm{m}$ W5 methods perform better than 2 WET-based methods that allow narrowing the peaks at $5 \%$ height by a factor of 3 as compared to 1D spectra (see Figure 4).

\subsection{Combination of multisuppression with Pure-Shift}

To go on improving the signal dispersion at low field, we merged multiple solvent elimination schemes with a TSE PSYCHE sequence (Figure 1), which was previously found as the best compromise for Pure-Shift spectroscopy at $43 \mathrm{MHz}$ [6]. Pure-Shift methods are known to induce sensitivity losses, which have been well characterized [14]. Here, SNRs for indole were found better for 4 W5-TSE PSYCHE close to $3 \%$ on average of the ${ }^{1} \mathrm{H} 1 \mathrm{D}$ (see Figure 3.B and Figure S3.B). Under these conditions, DMF and EA signals were reduced in a range of 500 to 1700 as compared to ${ }^{1} \mathrm{H}$ (see Figure 3.B and S4.B). In comparison, 2 and 3 W5-TSE PSYCHE allowed reaching better solvent suppression from 580 to 3333 but with worse averaged SNRs -close to $0.7 \%$ of the ${ }^{1} \mathrm{H}$ spectrum - since aromatics signals were very low sensitive (see Figure 2 with high zoom factors and S4 for more details).

2 WET180NOE-based TSE PSYCHE led to worse SNRs for indole from $0.7 \%$ for the successive version to $1.6 \%$ of the ${ }^{1} \mathrm{H}$ for the interlaved version better for sensitivity as already shown without the TSE PSYCHE block (see Figure 3 A,B). 2 WET180NOE versions gave access to comparable elimination performances to 4 W5-TSE PSYCHE. Moreover, 2 WET180NOE versions showed some decoupling artefacts flanking the aromatics from the indole derivative (Figure 2). These artefacts come either from non-ideal decoupling leading to side bands and / or from small imperfections of chunk reconstruction from the different experiments of the pseudo 2D scheme (see Figure 1).

Regarding resolution based on the linewidth at $5 \%$ height, all Pure-Shift experiments allowed reducing the linewidth by 2 to 3 linewidth compared to 1D W5 leading to indole peaks 11 times narrower than on the 1D spectrum (Figure 4). Thus, the novel merging $m$ W5 with TSE PSYCHE allowed multiplying resolution gain of each scheme taken separately. Moreover, in the perspective of monitoring applications, the repeatability of 4 W5TSE PSYCHE was evaluated to $2 \%$ over integrals for indole after 5 replicates.

\subsection{Sensitivity considerations}

As described above, the utilization of multiple elimination schemes could impact differently the sensitivity for signals of interest. For low concentrated samples, $\mathrm{m}$ W5 pulse sequences with conventional ${ }^{1} \mathrm{H}$ detection are the best solutions for the sake of sensitivity with significant resolution gains from 4 to 5 but with some J-modulations (see Figure S2). In the case of concentrated samples where sensitivity is not an issue and where efficient line narrowing is needed, the best alternative remains $m$ W5-TSE PSYCHE but with only 1 to $3 \%$ of the 1D sensitivity. 


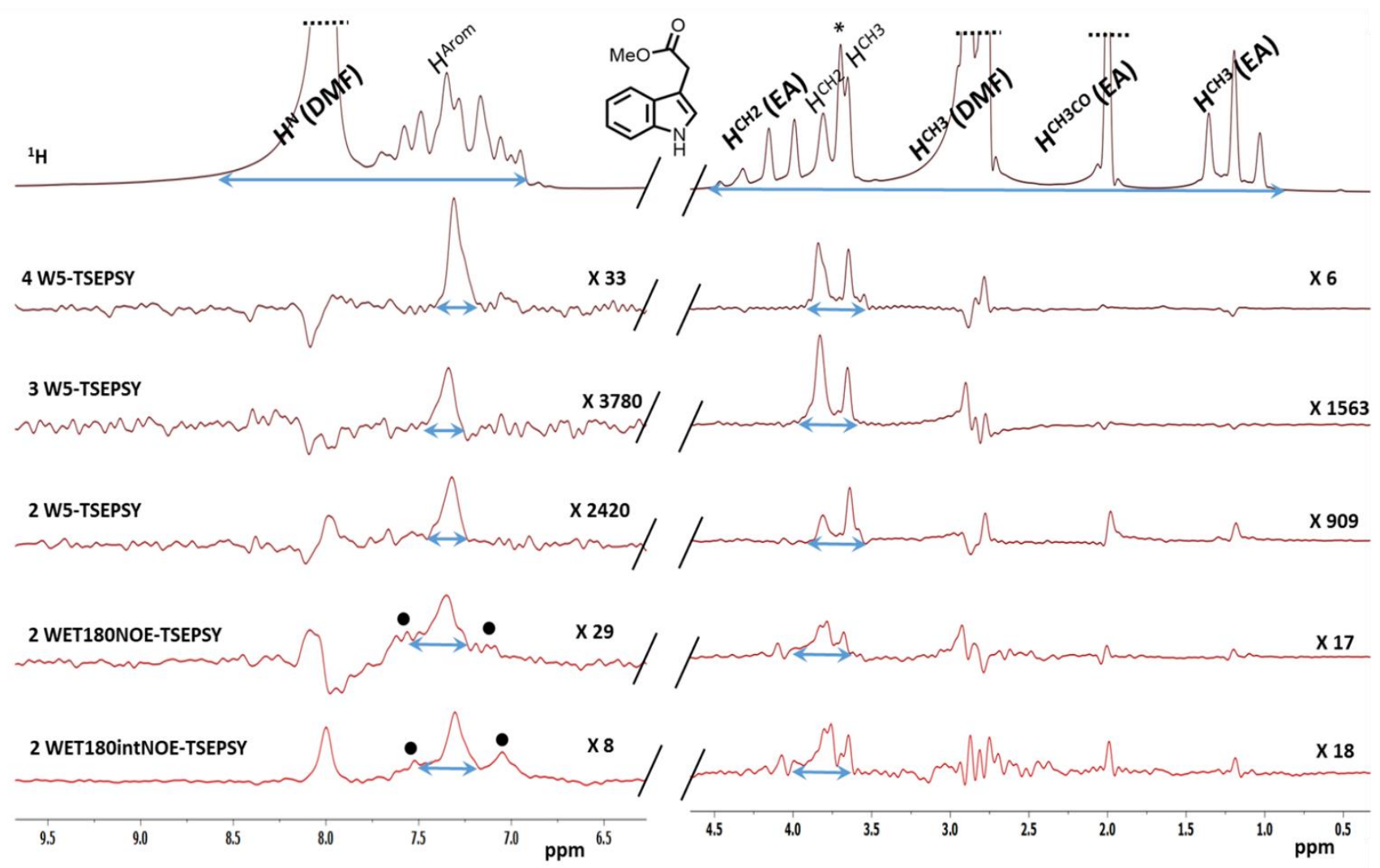

Figure 2. Different solvent eliminating methods combined with a TSE PSYCHE pulse sequence applied on the indole derivative in DMF/EA. Pulse sequences names are mentioned (see Figure 1) as well as the vertical zoom factors used for each spectra. * is an impurity and $\bullet$ are artefacts. Blue arrows indicate the linewidths that were used to evaluate resolution enhancements at $5 \%$ height.

A)
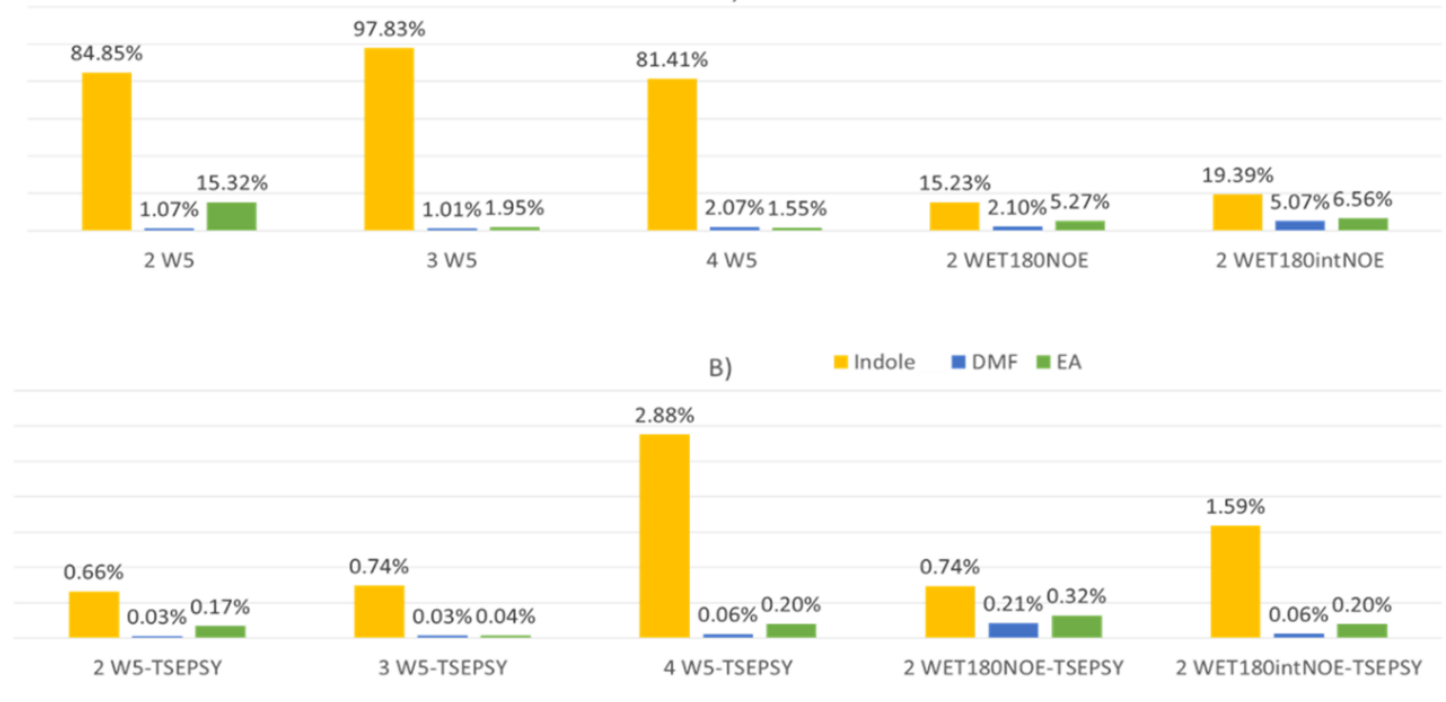
Figure 3. Averaged SNR as compared to $1 \mathrm{D}{ }^{1} \mathrm{H}$ for A) 1D solvent eliminated methods and B) combined with TSE PSYCHE version for the indole derivative, DMF and EA solvents.

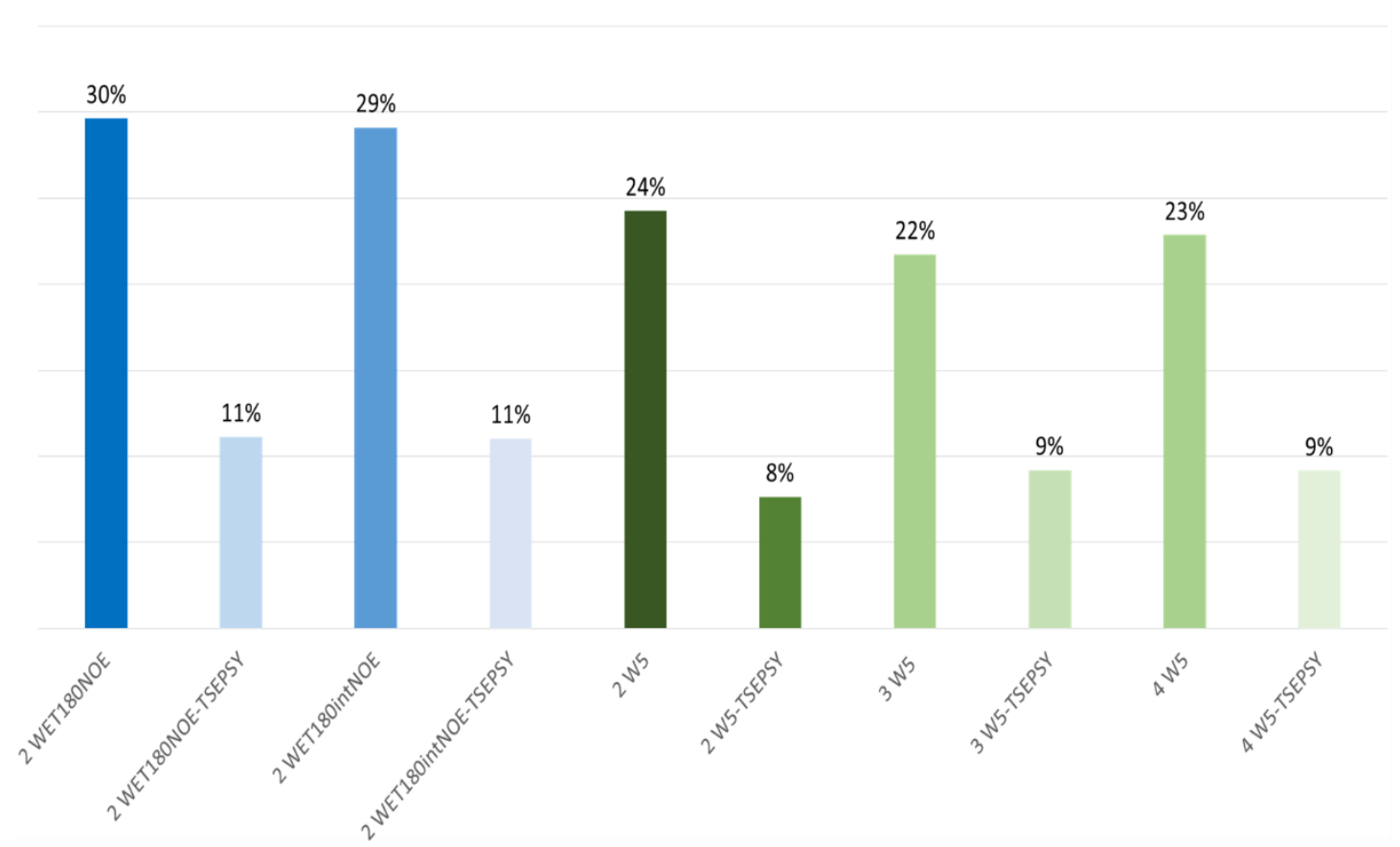

Figure 4. Averaged linewidth at $5 \%$ height obtained for different solvent elimination methods for indole derivative in DMF/EA as compared to ${ }^{1} \mathrm{H} 1 \mathrm{D}$ spectra.

\subsection{Application to the flow synthesis of benzoxanthenone 5}

Benchtop NMR already showed its potential in the context of flow chemistry as an essential element of self-optimizing autonomous flow reactors $[9,15,16]$. Thus, to enrich essential NMR developments on compact apparatus, we were interested in showing the potential of multi-suppression methods combined with TSE PSYCHE for analyzing complex chemical mixtures composed on bigger-sized molecules at low field. Regarding solvent suppression, we focused on $\mathrm{m}$ W5 methods that gave optimum results on the model samples. Thus, the synthesis of benzoxanthenone 5 by a cobaltcatalyzed oxidative dimerization of the starting adduct $\mathbf{1}$, previously reported [17] through a flow process, was carried out (see Experimental Part). As detailed on Figure 5 the compact NMR apparatus equipped with a flow cell is receiving the reactional mixture from the flow reactor. 
<smiles>C/C=C/c1cc(OC)ccc1O</smiles>

$1,[0.35 \mathrm{M}]$

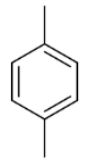

2, $[0.35 \mathrm{M}]$<smiles></smiles>

3, $\left[4.5 \times 10^{-3} \mathrm{M}\right]$

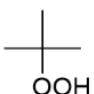

4, $[0.38 \mathrm{M}]$
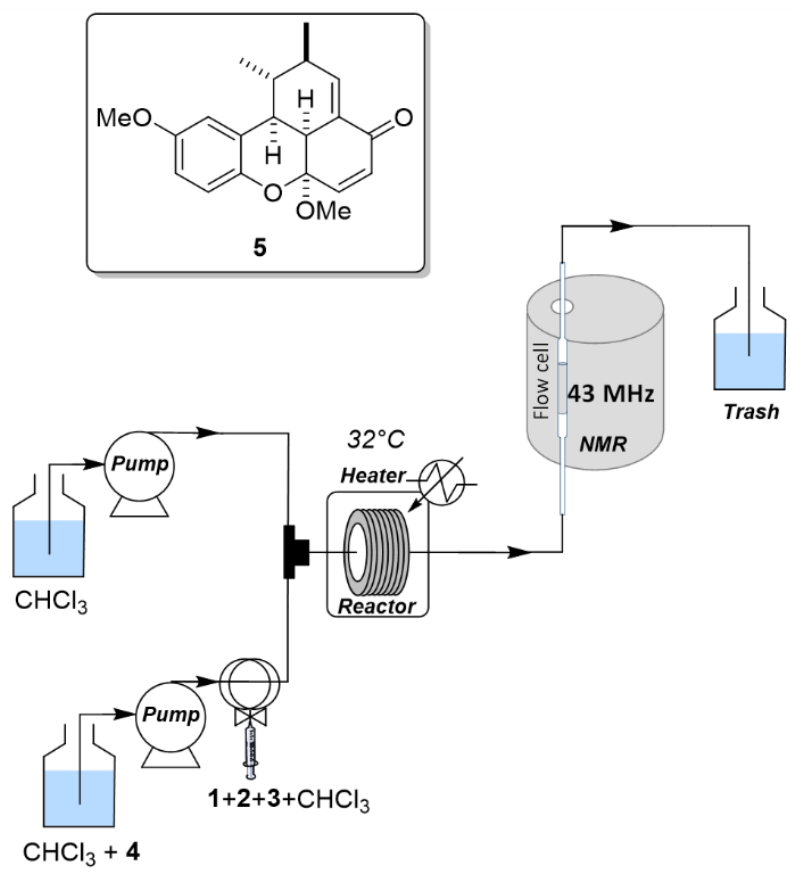

Figure 5. On-flow synthesis of benzoxanthenone 5, from the methoxypropenylphenol derivative $\mathbf{1}$ triggered by the tert-butylhydroperoxide $\mathbf{4}$ and catalyzed by cobalt catalyst 3 (condition 1 is mentioned see table 1). $p$-xylene is added as an internal reference for determining yields. After filling tubings and the flow-cell $(2 \mathrm{~mL})$, NMR spectra were acquired under stopped-flow conditions.

The flow synthesis of $\mathbf{5}$ was previously optimized [15] but to show the potential of the new NMR experiments, 4 different experimental conditions with different yields were investigated (see Table 1).

First, signal assignments were previously obtained for the starting compound $\mathbf{1}$ and the final compound $\mathbf{5}$ separately with the help of a 2D TOCSY map (see Figure S5 and for the derived assignment Table S1). Then, the performance of the pulse sequence elements introduced in this paper was evaluated. Ilustrative examples are shown in Figure 6, where comparisons are performed between TSE PSYCHE versus standard ${ }^{1} \mathrm{H}$ for reactant 1 , and between 1 W5 TSE PSYCHE and standard ${ }^{1} \mathrm{H}$ for product 5 . For compound $\mathbf{1}$, most of the signals are resolved in the ${ }^{1} \mathrm{H}$ spectrum: $\mathrm{Ha}, \mathrm{Hd}$ and $\mathrm{Hc}$. The effect of the homodecoupling can be seen at a glance on the signal of $\mathbf{1}$ where the $\mathrm{Ha}$ doublet is turned into a singlet in the
Pure-Shift spectrum but with some artefacts coming from an imperfect decoupling (Figure 6.A). Moreover, signals $\mathrm{He}$ and $\mathrm{Hf}$ can be separated thanks to the Pure-Shift approach. On product $\mathbf{5}$, the dimer of $\mathbf{1}$, it was essential to reduce the huge $\mathrm{CHCl}_{3}$ signal, and $1 \mathrm{~W} 5$ was used prior to the TSE PSYCHE scheme (see Figure 6.B). With this pulse sequence, it became possible to better visualize methyl groups $\mathrm{Hi}$ and $\mathrm{Hk}$ thanks to $\mathrm{J}_{\mathrm{HH}}$ collapsing. Other low intense $\mathrm{Hj}, \mathrm{HI}, \mathrm{Hm}$ and $\mathrm{Hn}$ signals could be detected and were better separated despite the loss of sensitivity due to the homodecoupling (see section 2.2 for this point). The aromatic area of product 5 was better resolved thanks to the combination of 1 W5 and TSE PSYCHE. In order to show the potential of such 1 W5-TSE PSYCHE pulse sequence it was further tested on the complete reaction mixture composed of 1, 2, 3, 4 and 5 . 

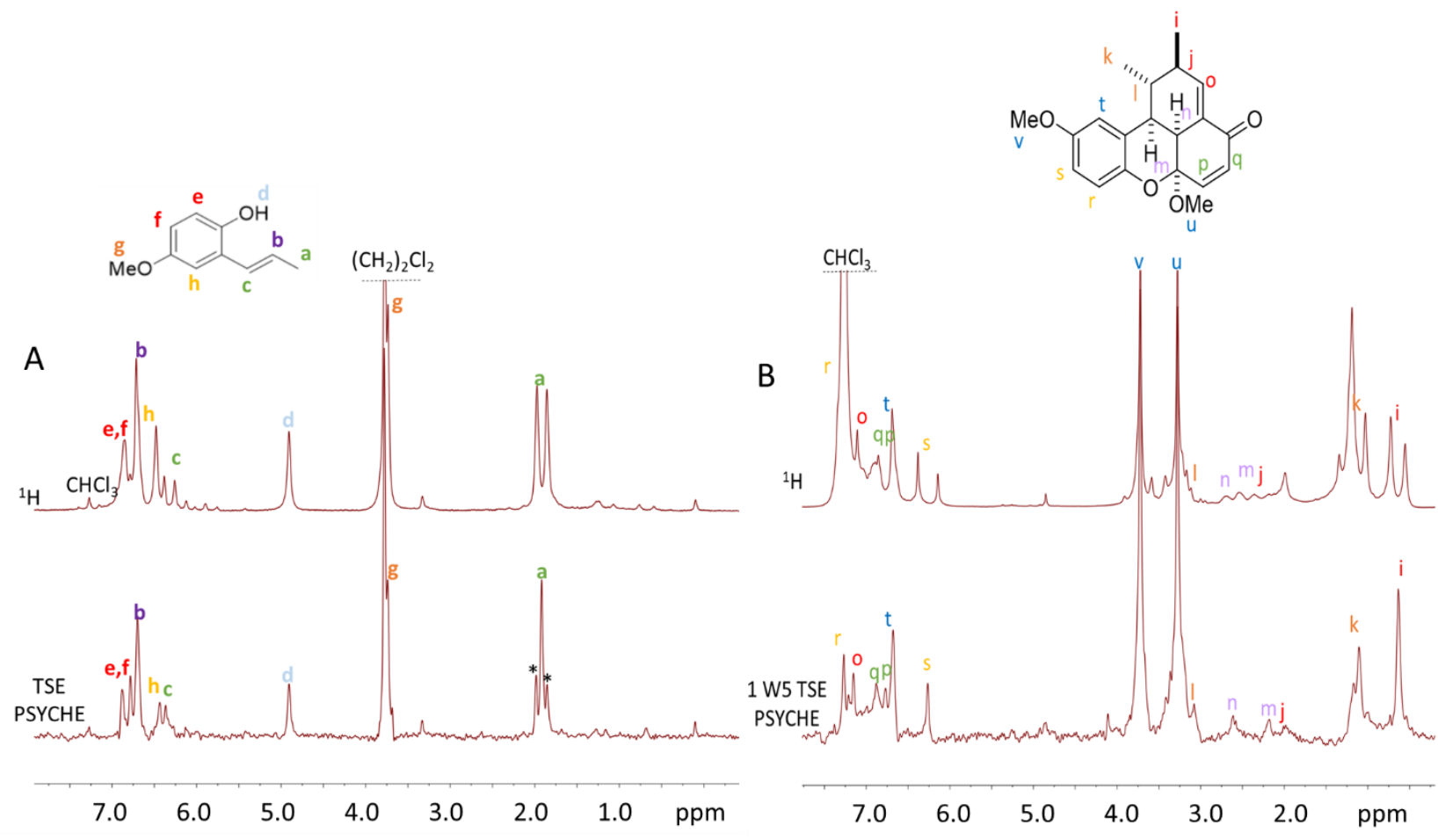

Figure 6. Comparison of standard ${ }^{1} \mathrm{H}$ (top) and TSE PSYCHE (bottom) for A) the starting reactant 1 in $\mathrm{CDCl}_{3}$ with residual $\left(\mathrm{CH}_{2}\right)_{2} \mathrm{Cl}_{2}$, and of standard ${ }^{1} \mathrm{H}$ (top) and 1 W5-TSE PSYCHE (bottom) B) the final product 5 in $\mathrm{CHCl}_{3} .{ }^{*}$ show homodecoupling artefacts. See ESI for signal assignments (Table S1)

\subsection{Potential of $\mathrm{m}$ W5-TSE PSYCHE}

1 W5-TSE-PSYCHE was found optimum to enhance the spectral resolution for this complex reacting mixture (see
Figure 7). 1 W5 was prefered over 2 W5 for removing huge signals of tBuOOH and $\mathrm{CHCl}_{3}$ since significant sensitivity losses from 20 to $40 \%$ (data not shown) arose from T2 evolution during the double W5 echo. Moreover, 1 W5 was sufficient enough to remove the two unwanted intense signals. 


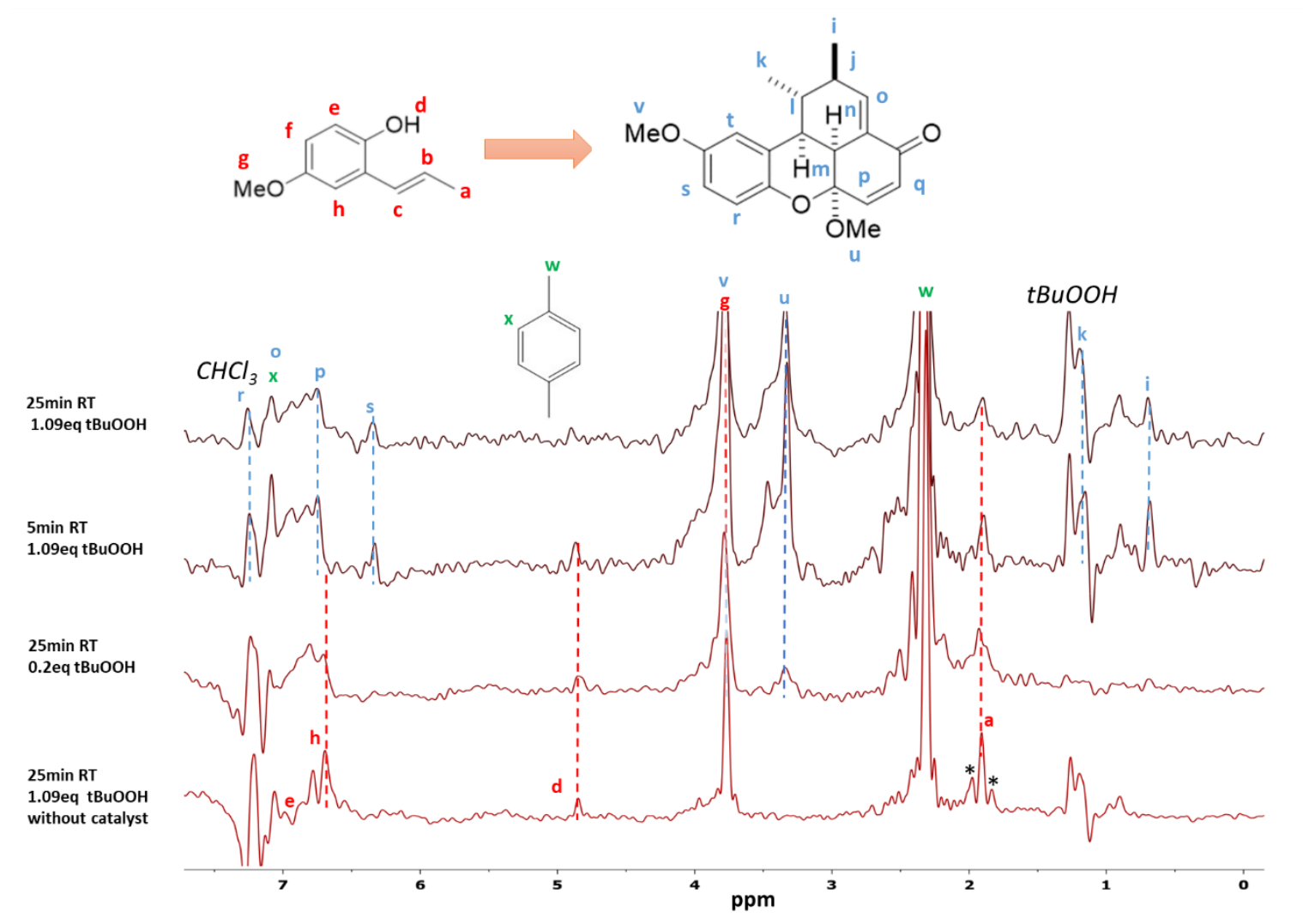

Figure 7. Comparison of 1 W5-TSE PSYCHE spectra for the 4 investigated reaction conditions specified on the left. Assignment of the starting 1 (in red), the internal reference (in green) and final 5 product (in blue) is added for showing a better signal recognition. ${ }^{*}$ show homodecoupling artefacts. See ESI for signal assignment (Table S1).

Monitoring several ${ }^{1} \mathrm{H}$ sites during a reaction is essential to visualize the structural changes in any moieties of the different molecules within the reaction mixture. Thus, the potential of 1 W5-TSE PSYCHE to detect different compounds in a reaction, was tested through 4 different reaction conditions (see Figure 7). The presence of only the starting product 1 without catalyst ( $0 \%$ yield), is confirmed with signals $\mathrm{Ha}, \mathrm{He}$ and $\mathrm{Hh}$ (in red Figure 7). When the oxidizing agent $\mathrm{tBuOOH}$ is added in default $(0.2 \mathrm{eq})$ a low concentrated amount of product $5(27 \%$ yield) is visible (see signal $\mathrm{Hu}$ in blue in Figure 6) as well as signals from starting reactant 1 . When the loading of $t \mathrm{BuOOH}$ is increased to $1.09 \mathrm{eq}$, yields of 70 and $91 \%$ at 5 and $25 \mathrm{~min}$ of residence time, respectively, were recorded (see Table 1 \& Figure 5), blue assigned signals $\mathrm{Hi}, \mathrm{Hk}, \mathrm{Hs}$, are better recognized for product $\mathbf{5}$ as well as the red assigned signal $\mathrm{Ha}$ that remains confirming the presence of the starting product 1 (Figure 6). 1 W5-TSE PSYCHE allows reducing the linewidth of ${ }^{1} \mathrm{H}$ signal by a range from 3 to 25 (see Figure S6 and S7). Although it retains only 1 to $4 \%$ of the ${ }^{1} \mathrm{H}$ sensitivity, sensitivity remains sufficient to detect the signals of interest (see Figure S7).

\section{Conclusion}

We introduced a new toolbox of solvent-suppression PureShift methods for the investigation of complex systems in reaction monitoring on compact low field instruments. An improved spectral resolution was reached thanks to the novel merging of gradient-based schemes by combining multiple W5 prior to the TSE PSYCHE. First, a model mixture composed on an indole compound with DMF and EA was investigated to show the potential of the new techniques. In this case, 4 W5TSE PSYCHE sequence allowed the reduction by 500 to 1700 of unwanted signals and to enhance the resolution by 11 as compared to $1 \mathrm{D}{ }^{1} \mathrm{H}$ while retaining between 2 to $3 \%$ of the $1 \mathrm{D}$ ${ }^{1} \mathrm{H}$ SNR. The merging of PS techniques with multiple elimination schemes multiply the performance of either PS or $\mathrm{m}$ W5 independently implemented.

The potential of this approach to better appreciate the composition of reaction mixtures for optimizing the conditions of flow synthesis was shown on a complex benzoxanthenone natural product analogue. 
Here, the total time for each experiment was between 7 to 14 min due to the pseudo 2D mode of the TSE PSYCHE scheme. Efforts to reduce the overall time is under progress with fast repetition techniques [18] and Non Uniform Sampling or NUS [19] in order to further accelerate the NMR measurement time and to make it compatible with the monitoring of faster chemical events. Thus, combining resolution-enhanced schemes could open new horizons for emerging applications of benchtop NMR on concentrated samples such as edible oils or biolfuids like urine.

\section{Experimental Section}

\section{Sample preparation}

\section{Model mixture}

A $500 \mathrm{mM}$ methyl indole-4-acetate solution was prepared by dissolving $473 \mathrm{mg}$ in $2.5 \mathrm{ml} \mathrm{DMF}$ and $2.5 \mathrm{ml}$ of EA. A peristaltic pump was used to generate the continuous flow- $1 \mathrm{~mL} \cdot \mathrm{min}^{-1}$. for the studied samples.

\section{Starting reactant 1 and product 5}

For evaluating the performance of the new implemented techniques a sample of $0.35 \mathrm{M}$ of 1 in $\mathrm{CDCl}_{3}$ and $0.18 \mathrm{M}$ of 5 in $\mathrm{CHCl}_{3}$ were prepared.

Synthesis of benzoxanthenone 5

The experimental setup consisted in two streams as depicted in Figure 5 The first stream, equipped with a PEEK injection loop $(1 \mathrm{~mL})$, was loaded with a solution of methoxypropenylphenol $1(0.35 \mathrm{M})$, cobalt catalyst $3(4.5 \times 10$ $\left.{ }^{3} \mathrm{M}\right)$ and $\mathrm{p}$-xylene $2(0.35 \mathrm{M})$ as the internal standard in $\mathrm{CHCl}_{3}$. The second stream contained a solution of $\mathrm{tBuOOH} 4$ (1.09 or 0.2 eq) in $\mathrm{CHCl}_{3}$ which was continuously pumped. Both streams were pumped with two independent pumps at the required flow rate, and met in a stainless steel T-shaped piece (internal volume: $0.57 \mu \mathrm{L}$ ). The resulting mixture was introduced in a PEEK reactor coil $(5 \mathrm{~mL}, 0.75 \mathrm{~mm}$ i.d.) heated at $32{ }^{\circ} \mathrm{C}$. The reactor outlet was connected to the by-pass system consisting of an NMR flow-cell and PEEK tubing for a total volume of $2 \mathrm{~mL}$. The flow rate was calibrated and optimized with sample solvents.

\begin{tabular}{lllllll}
$\begin{array}{l}\text { Table 1. } \\
\text { 1. Reaction } \\
\text { benzoxanthenone } \mathbf{5}\end{array}$ & conditions for the synthesis of & \\
\hline $\begin{array}{l}\text { Reaction } \\
\text { Conditions }\end{array}$ & $\begin{array}{l}\text { Flow rate } \\
(\mathrm{ml} / \mathrm{min})\end{array}$ & $\begin{array}{l}\text { Residence } \\
\text { time } \\
(\mathrm{min})\end{array}$ & $\begin{array}{l}\text { Eq. of } \\
\mathrm{tBuOOH}\end{array}$ & $\begin{array}{l}\text { Catalyst } \\
(\%)\end{array}$ & $\begin{array}{l}\text { Yield }^{\mathrm{a}} \\
(\%)\end{array}$ \\
\hline 1 & 0.2 & 25 & 1.09 & 1.3 & 91 \\
2 & 1.2 & 5 & 1.09 & 1.3 & 70 \\
3 & 0.2 & 25 & 0.2 & 1.3 & 27 \\
4 & 0.2 & 25 & 1.09 & 0 & 0 \\
\hline
\end{tabular}

[a] derived from quantitative $1 \mathrm{D}{ }^{1} \mathrm{H}$ by using $\mathrm{MeO}$ signal (13) for $\mathbf{5}$ and Me signal (1) for $\mathrm{p}$-xylene

\section{NMR}

All the spectra were recorded at $28.5^{\circ} \mathrm{C}$ using a ${ }^{1} \mathrm{H},{ }^{19} \mathrm{~F}, 43$ $\mathrm{MHz}$ Spinsolve from Magritek equipped with a gradient coil in the direction of the static magnetic field B0. The length of $90^{\circ}$ hard pulses was $10 \mu$ s at $0 \mathrm{dBW}$.

In a general manner, the receiver gain was optimized for each solvent eliminated sequence as a compromise between improving the sensitivity of lower signals and not reaching a signal saturation for the receiver.

WET: 2 different sequences were used: 2 WET180NOESY and 2 WET180intNOESY. The WET180 block is composed of four selective pulses applied on solvent signals, separated by gradients that are dedicated for vanishing selected signals (see Figure 1). For DMF/ EA system, gaussians with a length of $30 \mathrm{~ms}$ ( $33 \mathrm{~Hz}$ of selection area) applied at $8 \mathrm{ppm}$ allowed for selecting $\mathrm{H}^{\mathrm{N}}$ signal with a first WET and $6 \mathrm{~ms}$ gaussians (167 Hz of selection area) applied at 2 ppm allowed selecting the area composed on 2 Methyls of DMF, and 2 Methyls of EA. The mixing time of the NOESY block was fixed to $6 \mathrm{~ms}$ after its optimization for reducing fareway solvent effect.

$m$ W5: Multiple excitation sculpting W5 echoes flanked by gradients have been also used (see Figure 1). Nulling delays $d_{m}$ of each mW5 block have been finely tuned in order to periodically remove signals each $1 /\left(2 x d_{m}\right) \mathrm{Hz}$. All optimized delays $d_{m}$ are summarized in table 2 .

Table 2. Nulling $d_{m}$ delays in $\mu$ s for multiple W5 schemes ( $m$ W5) implemented for removing solvent signals of the investigated mixtures.

\begin{tabular}{|c|c|c|c|c|c|c|}
\hline $\begin{array}{l}\text { Indole in } \\
\text { DMF } \\
\text { / EA }\end{array}$ & m W5 & $\begin{array}{l}\mathrm{H}^{\mathrm{N}} \\
(\mathrm{DMF})\end{array}$ & $\begin{array}{l}\mathrm{CH}_{2} \\
\text { (EA) }\end{array}$ & $\begin{array}{l}2 \times \mathrm{CH}_{3} \\
\text { (DMF) }\end{array}$ & $\begin{array}{r}\mathrm{CH}_{3} \mathrm{CC} \\
(\mathrm{EA}\end{array}$ & $\begin{array}{l}\mathrm{CH}_{3} \\
\text { (EA) }\end{array}$ \\
\hline & $2 W 5$ & 2225 & 5494 & 2225 & \multicolumn{2}{|c|}{5494} \\
\hline & 3 W5 & 2225 & 5494 & 2225 & 5494 & 500 \\
\hline & $4 W 5^{[a]}$ & 2225 & 5494 & 2225 & 5494 & 500 \\
\hline \multirow[t]{2}{*}{$\begin{array}{c}\text { Product } \\
\mathbf{5}\end{array}$} & m W5 & $\mathrm{CHCl}_{3}$ & & & & \\
\hline & $1 \mathrm{~W} 5$ & 2000 & & & & \\
\hline $\begin{array}{l}\text { Reaction } \\
\text { mixtures }\end{array}$ & $\mathrm{m}$ W5 & $\mathrm{tBuOOH}$ & $\mathrm{CHCl}_{3}$ & & & \\
\hline & $1 \mathrm{~W} 5$ & \multicolumn{2}{|c|}{1914} & & & \\
\hline
\end{tabular}

[a] The 2 first W5 of the 4 W5 scheme are dedicated to remove DMF signals 
All 2 WET and W5 1D spectra were recorded in 144 scans with a repetition time of $3 \mathrm{~s}$ for the indole in DMF system, leading to an overall experiment duration of $7 \mathrm{~min}$ and in 336 scans with a repetition time of $3 \mathrm{~s}$ for the indole in DMF/EA system leading to an overall experiment duration of $14 \mathrm{~min}$ for sake of comparison with PS techniques.

In the TSE PSYCHE pulse sequence, a double saltire CHIRP pulse of $2 \times 30 \mathrm{~ms}$ was used with a bandwidth of $2.5 \mathrm{kHz}$ and a smoothing of $10 \%$, applied simultaneously with a $0.8 \mathrm{G}_{\mathrm{cm}} \mathrm{cm}^{-1}$ gradient. An angle of $25^{\circ}$ was chosen as a compromise between sensitivity and decoupling sidebands intensity. Moreover two $5 \mathrm{~ms}$ CHIRP pulses with $2.5 \mathrm{kHz}$ bandwidth and $10 \%$ smoothing were applied simultaneously with a gradient of $1.6 \mathrm{G} \mathrm{cm}^{-1}$ to suppress zero quantum coherences.

Finally, solvent suppression schemes along with TSE PSYCHE experiments also known as broadband homonuclear decoupling were implemented as pseudo $2 \mathrm{D}$ experiments by repeating a $1 D$ while incrementing the duration $t_{1 / 2}$. The free Induction decays (FIDs) were divided into short periods called "chunks" (33ms was found as optimal) in order to prevent the J-coupling evolution. All the chunks were then stored and combined to reconstruct a hybrid 1D FID that underwent a Fourier transform.

For DMF/ EA indole all 2D PS matrices were acquired with $8192 \times 16$ points and 16 scans per experiment with $3 \mathrm{~s}$ for the repetition time, lasting $14 \mathrm{~min}$. The experimental time is the same for all the PS experiments on a given sample, in order to compare their respective sensitivity. Conventional $1 \mathrm{D}{ }^{1} \mathrm{H}$ experiments were also recorded with 8192 points within the same duration (336 scans) for the sake of comparison.

For benzoxanthenone $\mathbf{5}$ and starting reactant $\mathbf{1}$ alone or under reaction, all 2D PS matrices were acquired with $8192 \times 16$ points and 16 scans per experiment with $3 \mathrm{~s}$ for the repetition time, lasting $14 \mathrm{~min}$. Quantitative 1D NMR experiment also recorded with $3 \mathrm{~s}$ repetition time and with 16 scans for calculating yields from para-xylene. T1 times have been measured with $T 1^{\max }=1 \mathrm{~s}$, a repetition time of 3s was chosen as a compromised between quantitative conditions $\left(3 \times \mathrm{T} 1^{\mathrm{max}}\right)$ and short acquisition times: $1 \mathrm{~min}$

NMR data processing: All the NMR experiments were recorded within the programming interface Spinsolve Expert. Signal processing were achieved with Mnova 12.0. It appeared essential to carefully adjust the apodization function for each technique studied here, in order to find the best compromise between resolution and sensitivity. For ${ }^{1} \mathrm{H}$ 1D standard NMR, Traficante function (Traf) and an exponential function both with a $1.0 \mathrm{~Hz}$ line broadening factor have been chosen. For all other techniques decribed above, the best compromise for Traficante function (Traf) and an exponential function is $0.3 \mathrm{~Hz}$ as a line broadening factor. Phase correction was done manually and automatically or via pre-recorded zero and first- order parameters. For the model mixture, spectra were referred with the solvent signal $\mathrm{H}^{\mathrm{N}} \mathrm{DMF}$ at $8.00 \mathrm{ppm}$. For reaction mixtures,spectra were referred with the xylene methyls at $2.32 \mathrm{ppm}$. For all spectra, an additional baseline correction was achieved through a Whitthaker smoother function.

\section{Acknowledgements}

S. K. warmly acknowledges the French National Center for Scientific Research (CNRS) for a one year postoctoral fellowship in the field of the Emergence@INC2019 ARESTATION project. S. K. also acknowledges Dr. Vasudevan Natarajan for assistance with the flow apparatus. J. F. warmly thanks his partner Sandrine Bouchet for an unfailing precious assistance.

Keywords: benchtop NMR - multiple solvent suppression • Pure-Shift NMR • flow chemistry • resolution enhancement

[1] D. A. Foley, E. Bez, A. Codina, K. L. Colson, M. Fey, R. Krull, D. Piroli, M. T. Zell, B. L. Marquez, Anal. Chem. 2014, 86, 1200812013.

[2] K. Singh, B. Blümich, Trends Anal. Chem. 2016, 83, 12-26.

[3] B. Gouilleux, B. Charrier, S. Akoka, F.-X. Felpin, M. Rodriguez-Zubiri, P. Giraudeau, Trends Anal. Chem. 2016, 83, 65-75

[4] G. Assemat, B. Gouilleux, D. Bouillaud, J. Farjon, V. Gilard, P. Giraudeau, M. Malet-Martino, J. Pharm. Biomed. Anal. 2018, 160, 268-275.

[5] K. Zangger, Progress in Nuclear Magnetic Resonance Spectroscopy 2015, 86-87, 1-20.

[6] T. Castaing-Cordier, D. Bouillaud, P. Bowyer, O. Gonçalves, P. Giraudeau, J. Farjon, Chem. Phys. Chem. 2019, 20, 736-744.

[7] B. Gouilleux, B. Charrier, S. Akoka, P. Giraudeau, Magn. Reson. Chem. 2017, 55, 91-98.

[8] B. Picard, B. Gouilleux, T. Lebleu, J. Maddaluno, I. Chataigner, M. Penhoat, F.-X. Felpin, P. Giraudeau, J. Legros, Angew. Chem. Int. Ed. 2017, 56, 7568-7572.

[9] D. Cortés-Borda, E. Wimmer, B. Gouilleux, E. Barré, N. Oger, L. Goulamaly, L. Peault, B. Charrier, C. Truchet, P. Giraudeau, M. Rodriguez-Zubiri, E. Le Grognec, F.-X. Felpin , J. Org. Chem., 2018, 83, 14286-14299

[10] S. H. Smallcombe, S. L. Patt, P. A. Keifer, J. Magn. 1995, 117, $295-$ 303.

[11] R. T. Mckay, Concept in Magn. Reson. 2011, 38A, 197-220.

[12] S. A. Willis, G. Zheng, A. M. Torre, T. Stait-Gardner, W. Price, J. Phys. Chem. A, 2018, 122, 9712-9720

[13] M. Foroozandeh, R. W. Adams, P. Kiraly, .M. Nilsson, G. A. Morris, Chem. Commun. 2015, 51, 15410-15413

[14] L. Castañar, Magn. Reson. Chem. 2017, 55, 47-53.

[15] V. Sans, L. Porwol, V. Dragone, L. Cronin, Chem. Sci. 2015, 6, 12581264 
[16] E. C. Aka, E. Wimmer, E. Barré, N. Vasudevan, D. Cortés-Borda,T. Ekou, L. Ekou, M. Rodriguez-Zubiri, F.-X. Felpin, J. Org. Chem. 2019, 84, 14101-14112.

[17] P. Giraudeau, F. X. Felpin, React. Chem. Eng., 2018, 3, 399-413.
[18] J. Farjon, Magn. Reson. Chem. 2017, 55, 883-892

[19] D. M. Korzhnev, I. V. Ibraghimov, M. Billeter, V Y. Orekhov, J. Biomol. NMR, 2011, 21, 263-268. 
Entry for the Table of Contents (Please choose one layout)

Layout 1:

\section{ARTICLE}

Text for Table of Contents

Merging to multiply resolution power for low field NMR

Combining gradient-based techniques on a benchtop spectrometer efficiently removes up to 6 intense solvent signals and enhances more than $\times 10$ the resolution of relevant signals thanks to the novel $\mathrm{m}$ W5 TSE PSYCHE experiment. This strategy is applied to the flow synthesis of a complex benzoxanthenone in mixture.
S. Kunjir, M. Rodriguez-Zubiri, V. Coeffard, F.-X. Felpin, P. Giraudeau and J. Farjon*

Page No. - Page No.

Merging gradient-based methods to improve benchtop NMR spectroscopy: A new tool for flow reaction optimization 